
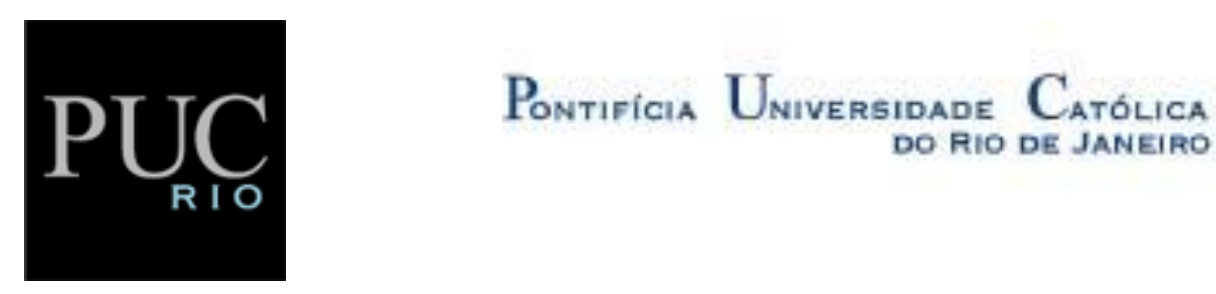

DO RIO DE JANEIRC

Alessandra Linhares Bula Biliani

A precarização das políticas intersetoriais e o impacto na permanência das crianças e adolescentes na escola

Artigo Científico como modalidade para o Trabalho de Conclusão do Curso de Especialização em Assistência Social e Direitos Humanos - PUC Rio, como requisito parcial para o título de Especialista em Assistência Social e Direitos Humanos.

Orientadora Prof ${ }^{a}$. Dr ${ }^{\mathrm{a}}$ Valéria Pereira Bastos

Rio de Janeiro

Fevereiro de 2017 


\title{
A precarização das políticas intersetoriais e o impacto na permanência das crianças e adolescentes na escola.
}

\author{
Alessandra Linhares Bula Biliani ${ }^{1}$
}

\begin{abstract}
Resumo
O presente artigo tem por finalidade analisar a partir da experiência vivenciada como articuladora local do Projeto Aluno Presente, viabiizado através do trabalho desenvolvido pela Organização Não Goveramental Cidade Escola Aprendiz, no período de novembro de 2014 a dezembro de 2016, a precariedade das políticas públicas no seu aspecto intersetorial, no que diz respeito à permanência das crianças e adolescentes nas escolas no bairro Senador Camará, principamente, os residentes nas favelas do Rebu, Coreia e Taquaral, e assim evidenciar com isso as fragilidades causadas pela desigualdade social que tem como reflexo também, a não interlocução eficiente entre as políticas sociais, o que impossibilita o acesso a garantia de direitos dos cidadãos, em especial, em territórios conflagrados dominados por grupos criminosos.
\end{abstract}

Palavras-Chave: Educação; Intersetorialidade; Território; Evasão escolar; Projeto Aluno Presente

\section{The precariousness of intersectoral policies and their impact on the permanence of children and adolescents in school.}

\begin{abstract}
The purpose of this article is to analyze, from the experience lived as a local articulator of the Present Student Project, through the work developed by the Non Governmental Organization Cidade Escola Aprendiz, from November 2014 to December 2016, the precariousness of public policies In its intersectoral aspect, regarding the permanence of children and adolescents in schools in the Senador Camará neighborhood, principally those living in the favelas of Rebu, Korea and Taquaral, and thus highlighting the fragilities caused by social inequality, which also reflects The lack of efficient dialogue between social policies, which makes access to citizenship impossible, especially in conflict-ridden territories dominated by criminal groups.
\end{abstract}

Keywords: Education; Intersectoriality; Territory; School evasion; Present Student Project;

\footnotetext{
${ }^{1}$ Pedagoga e aluna de Pós Graduação em Assistência Social e Direitos Humanos da PUC-Rio.
} 


\section{Introdução}

O presente artigo tem por finalidade analisar a precariedade das políticas públicas no seu aspecto intersetorial, no que diz respeito à permanência das crianças e adolescentes nas escolas no bairro Senador Camará, precisamente, nas favelas do Rebu, Coreia e Taquaral no período compreendido entre dezembro de 2014 a novembro de 2016.

O recorte da análise terá como referência o Projeto Aluno Presente que foi pensado a partir de uma iniciativa da antiga secretária de educação, respaldado no ultimo censo do IBGE/2010 que apontou cerca de 24.000 mil crianças e adolescentes entre 6 e 14 anos que se encontravam fora das escolas ou em risco de evasão. Neste sentido, começou as mobilizações para implantação de um projeto que pudesse intervir diretamente nesta problemática no sentido de garantir o direito universal, conforme preceitua a Constituição Federal (1988):

Art. 227. É dever da família, da sociedade e do Estado assegurar à criança, ao adolescente e ao jovem, com absoluta prioridade, o direito à vida, à saúde, à alimentação, à educação, ao lazer, à profissionalização, à cultura, à dignidade, ao respeito, à liberdade e à convivência familiar e comunitária, além de colocálos a salvo de toda forma de negligência, discriminação, exploração, violência, crueldade e opressão. (BRASIL, 1988)

A partir deste contexto o projeto concorreu ao financiamento pela Fundação Education Above All, organização do Qatar que trabalha com projetos voltados para educação e através do programa chamado Educate a Child e conseguiu o financiamento, em parceria com a Secretaria Municipal de Educação do Rio de Janeiro. Contudo a Prefeitura do Rio de Janeiro não poderia ser gestora do capital advinda da Fundação Education Above All, por prérequisitos estabelecidos no edital do concurso, que a instituição receptora do capital deveria ser de cunho não governamental, foi onde indicaram a ONG Associação Cidade Escola Aprendiz por ter uma expertise na área da educação e já ter trabalhado com a Prefeitura do Rio de Janeiro em vários projetos voltados para área de educação.

Nesse contexto, fomos incorporadas à equipe e nossa experiência no projeto Aluno Presente ocorreu entre o período de fevereiro de 2014 a dezembro de 2016, onde a missão era promover ações que pudessem garantir o direito ao acesso à educação básica às crianças e adolescentes de 06 a 14 anos na cidade do Rio de Janeiro, e as atividades desenvolvidas baseava se principalmente na identificação e localização daqueles que não foram matriculados e na prevenção da evasão escolar. Neste contexto, não podemos 
deixar de trazer a tona um dos fatores, que ao nosso ver contribuem para o retrocesso de inúmeras ações na área social que é o modelo neoliberal que tem impactado a população, oriunda de periferias. Onde o estado maximiza o mercado e minimiza as ações voltadas para a política social, deixando que a sociedade civil ocupe este espaço, através das ONGs, portanto, as mazelas causadas pela desigualdade social, tornam se invisíveis ao poder público, mas impactadas nas vidas das pessoas que vivem nas favelas como a falta de saneamento básico, o tráfico de drogas, homens armados, falta infraestrutura, desempregos e falta segurança pública. Moradores que residem em favelas têm mais dificuldade na hora de conseguir trabalho, pois o empregador logo argumenta em dia de operação policial se ele ira faltar, pois não tem como sair de casa em meio ao conflito entre policiais e grupos armados, assim ficando mais uma vez os moradores de favelas sem oportunidade de trabalho para sustentar sua família. Casas mal ventiladas com esgoto a céu aberto trazendo problemas respiratórios para a população. A falta de médicos nos postos de saúde, pois não querem trabalhar nestes territórios onde há constantes conflitos entre grupos criminosos, prejudicando o atendimento à população, tendo sempre que fechar as portas em dias de conflitos.

Levantamentos feitos por órgãos competentes, afirmam que os países onde a desigualdade social é elevada, também registram índices igualmente elevados de outros fatores negativos, tais como: violência e criminalidade, desemprego, educação precária, falta de acesso a serviços públicos de qualidade, entre outros fatores que aumentam o contexto da vulnerabilidade social de seus moradores.

\section{A fragmentação das políticas públicas versus a importância da intersetorialidade}

A partir da realização da $11^{\text {a }}$ Conferência Nacional de Saúde realizada em 2007 a defesa da intersetorialidade passou a ser ponto de pauta das ações, pelo fato de se constituir como estratégia fundamental para a melhoria das condições de saúde da população brasileira (BRASIL, 2007).

Assim sete anos após a implantação da Lei Orgânica de Assistência Social - LOAS não havia qualquer documento da Secretaria da Assistência Social do extinto Ministério do Desenvolvimento Social e Combate à Fome (SAS/MDS) que referenciasse a articulação intersetorial e interfaces entre as três políticas que compõem a Seguridade Social (RAICHELIS, 2000). 
Já no contexto do SUAS (2005) houve uma inovação neste aspecto, pois a PNAS (2004) já trazia em seu bojo que a intersetorialidade, juntamente com a descentralização e a territorialização constituíam-se como um dos principais pressupostos da assistência social como política pública.

Os conteúdos da PNAS (2004) acerca da intersetorialidade são ratificados no texto da resolução 109 de 11/11/2009, que trata da tipificação nacional dos serviços socioassistenciais e sobre a sua regulação. De modo que no contexto da busca pela qualidade de vida da população, a PNAS (2004) ultrapasse os recortes setoriais que, tradicionalmente, fragmentaram as políticas sociais, sobretudo, a de assistência social e registra, também, que os serviços de proteção social tem estreita interface com o sistema de garantia de direitos, exigindo, muitas vezes, uma gestão mais complexa e compartilhada com o Poder Judiciário, o Ministério Público e órgãos do poder executivo.

Com a atuação há dois anos no projeto na Cidade do Rio de Janeiro, podemos ter algumas percepções sobre a falta de interlocução das políticas públicas, isto porque se os programas funcionassem como deveria a escola poderia ser um polo catalizador das ações e construir uma rede de serviços, com o posto de saúde local para dar atendimento a esta criança, na garantia do atendimento pleno. Assim podemos ver que os programas realmente são falhos e não têm a eficácia que deveriam ter como é o caso do Programa Saúde na Escola (PSE), política intersetorial da Saúde e da Educação, instituído em 2007, mas que não surte o efeito necessário para mitigar ou erradicar as demandas isoladas.

O Programa Saúde na Escola (PSE) fora estabelecido para articular ações voltadas para promover saúde e educação integral, às crianças, adolescentes, jovens e adultos da educação pública brasileira. Contudo a articulação intersetorial das redes públicas de saúde/educação é frágil, na implementação e desenvolvimento das ações do PSE nos territórios. Não implica somente em ofertas de serviços num mesmo território, o que deve se manter são as ações, a partir da conformação de redes de corresponsabilidade. Entretanto, o que devemos colocar em questão é: como esses serviços estão se articulando no território, qual o padrão comunicacional estabelecido entre as diferentes equipes e quais os serviços estão acontecendo e qual o modelo de atenção/gestão estão sendo reproduzidos de fato nos territórios.

Durante o acompanhamento de alunos infrequentes de uma escola da rede municipal de ensino, constatamos um caso de uma adolescente infrequente no sistema da escola, e ao realizar visita domiciliar para entender os motivos das 
faltas, constatamos que a aluna possuía diversas queloides pelo corpo, visíveis e que o problema ocasionava bullying por parte dos demais colegas de classe, e por consequência o desinteresse da jovem ao ambiente escolar, uma vez que devido a esta situação ela decidiu não mais voltar à escola.

$\mathrm{Na}$ ocasião da visita à família, a mãe foi encaminhada pelas articuladoras do projeto ao posto de saúde local e orientada a comparecer a escola para explicar a situação, objetivando evitar que a evasão escolar fosse caracterizada como desinteresse da aluna, e não como uma questão a ser resolvida por conta do sofrimento pelo fato de ser acometida de bullying pela classe.

Paralelo a esta questão o projeto continuou acompanhando o caso e constatou que durante este tempo não teve nenhum tipo de contato por parte da escola à família, principalmente, no que diz respeito à saúde da aluna, uma vez que o Programa Saúde na Escola - PSE poderia ter sido acionado para prestar o atendimento necessário, evitando que a adolescente ficasse identificada como evadida do contexto escolar.

Neste sentido, evidenciamos que a falta de articulação entre as áreas de educação e saúde no primeiro momento fez com que a aluna fosse classificada como evadida, mas através da intervenção do projeto, foi possível efetivar os devidos encaminhamentos por parte do posto que a encaminhou para hospital para realizar a cirurgia e desta forma a questão foi resolvida.

Portanto, ficou claro em nossa análise que a desistência pela escolarização através do bullying sofrido pela adolescente se configurou como mais uma consequência da falta de articulação entre as políticas, já que neste caso a escola poderia ter acessado diretamente a política de saúde para encaminhamento da jovem e consequente resolução da questão que ocasionava em suas constantes faltas e posterior evasão. Sendo assim fica evidente que

[...] a intersetorialidade é uma ação que integra as diferentes políticas sociais para superar, solucionar os problemas complexos, multifacetados, que atendam o cidadão em sua totalidade. Mas, para que esta ação tenha êxito, é necessário construir uma nova concepção de gestão das políticas públicas, envolvendo o planejamento, a execução e o controle social na prestação de serviços sociais públicos. Isso requer uma inovação na forma de articular os diversos segmentos da organização governamental e de seus interesses (FAUSTINO, 2014. p.161).

Considerando que o fenômeno das OOSC "Out Of School Children" (criança fora da escola) é multifatorial, o poder público em parceria como o Projeto Aluno Presente devido às demandas e necessidades encontrada no trabalho de campo e com a finalidade de articular os diferentes órgãos governamentais na busca de efetivar ações intersetoriais instituíram um Grupo 
de Trabalho (GT) Intersetorial composto pelas seguintes secretarias: Secretaria de Educação, Secretaria de Saúde e Secretaria de Desenvolvimento Social, além da Casa Civil.

O GT Intersetorial foi instituído através da publicação no Diário Oficial do município do Rio de Janeiro, e se configurou como estratégia fundamental para a articulação dos serviços de educação, saúde e assistência social nos territórios e buscava com esta ação efetivar ações, conforme descrito abaixo:

Além do GTI-M, fazem parte da estratégia de governança do PSE Carioca reuniões locais entre a direção ou representantes das Unidades Escolares, das Unidades de Atenção Primária à Saúde e dos CRAS. Essas reuniões terão o objetivo de identificar as necessidades locais, planejar as atividades e avaliar as ações específicas e essenciais de seus respectivos territórios, tendo suas respectivas datas sendo publicadas no Diário Oficial do Município (RIO DE JANEIRO, 2015, p. 223)

A partir das diretrizes traçadas pelos técnicos do nível central das secretarias envolvidas, as equipes de campo davam prosseguimento ao planejamento (em âmbito local) com os agentes dos serviços, implementando as estratégias para efetivação da rede de proteção às crianças e adolescentes identificadas pelo projeto.

A intenção é de se ter uma maior integração entre os equipamentos físicos das políticas públicas e essas reuniões mostram-se como sendo ideais para que isso aconteça. A cada reunião foi crescendo gradativamente a credibilidade e a aceitação do projeto Aluno Presente pelos órgãos e equipamentos, o que acaba por dinamizar as atividades e trabalho do projeto.

Através das reuniões realizadas nos GTIs, foram identificadas demandas que impossibilitavam ou dificultavam 0 acesso e permanência de crianças/adolescentes nas unidades escolares. Questões referentes a garantia de direitos do cidadão se fizeram presentes nas reuniões, principalmente, através do impedimento de matrículas de crianças/jovens que não possuíam Registro Civil de Nascimento.

Mesmo compreendendo que a falta de documentação não se configura como impeditivo para acesso à educação, já que é direito previsto em lei, estes obstáculos ainda persistiam no cotidiano. Desta forma, uma maior articulação intersetorial se faz necessária na garantia dos direitos sociais, já que as políticas precisam estar integradas para possibilitar o acesso dos cidadãos aos benefícios sociais, criando mecanismos internos e externos á sua efetivação, conforme preceitua a Constituição Federal Brasileira, em seu artigo 6º: 
"São direitos sociais a educação, a saúde, a alimentação, o trabalho, a moradia, o transporte, o lazer, a segurança, a previdência social, a proteção à maternidade e à infância, a assistência aos desamparados, na forma desta Constituição." (BRASIL,1988)

A educação é um direito, portanto, cabe a escola efetivar a matrícula no ensino fundamental mesmo sem a documentação exigida inicialmente, e, posteriormente, a unidade articularia intersetorialmente para que família tenha acesso à documentação, em conjunto principalmente com os Centros de Referência de Assistência Social - CRAS.

No entanto, esse movimento não ocorre com a mesma celeridade e articulação necessária, assim, as escolas por falta de conhecimento acabam recusando a matrícula da criança sem interagir com outros órgãos que poderiam auxiliar neste processo de acesso a um dos direitos básicos de cidadania.

\section{A precarização das políticas públicas em territórios conflagrados ${ }^{2}$}

A partir da atuação do projeto Aluno Presente nos territórios conflagrados $^{2}$ aqui entendido como aqueles espaços no qual a constante guerra entre traficantes de drogas e a polícia acontece diariamente no território deixando a população em total vulnerabilidade social, pois ostentação de homens fortemente armados na comunidade e grande venda de drogas é uma constante, fazendo com que a população residente desses locais se torne refem da violência.

\footnotetext{
O conceito de vulnerabilidade ao tratar da insegurança, incerteza e exposição a riscos provocados por eventos socioeconômicos ou ao não-acesso a insumos estratégicos apresenta uma visão integral sobre as condições de vida dos pobres, ao mesmo tempo em que considera a disponibilidade de recursos e estratégias para que estes indivíduos enfrentem as dificuldades que Ihes afetam (VIGNOLI e FILGUEIRA, 2001, apud AMBRAMOVAY, 2002, p. 34 -35).
}

Em novembro de 2015 foi identificada uma criança com idade de 10 anos de idade que nunca havia passado pela rede municipal de ensino devido a falta de Registro Civil de Nascimento, na busca de agilizar o processo, orientamos a responsável retornar ao hospital onde a criança nasceu e solicitar segunda via da Declaração de Nascido Vivo - DNV, pois o que ela estava em mãos, não tinha como dar entrada cartorial para emissão do documento, tendo em vista o 
desgaste porém por falta de orientação necessitou do acompanhamento da articuladora local para obter a documntação necessária que passou onze anos de vida sem acesso as ações promovidas pelas políticas públicas.

Situações como esta, ocorriam diariamente e inúmeras vezes nos territórios precarizados e empobrecidos de serviços e de conhecimento por parte da sociedade, oriundas de favelas. Os equipamentos públicos se aproveitam da falta de conhecimento da população e ficam dando encaminhamentos equivocados, e sem fundamentos para as famílias que dependem de seus serviços, o que dificulta na resolução de casos simples como o que vimos acima e acabam postergando e agravando situações como estas, pela má orientação, o que faz com que a família fique a mercê do atendimento ofertado pelos funcionários que trabalham nos equipamentos públicos ${ }^{3}$.

Entendemos que os usuários dos serviços que apresentem a mesma demanda da família que exemplificamos, precisam ser encaminhados para os outros serviços públicos complementares que viabilissem o atendimento de suas necessidades, tais como: CRAS, Conselho Tutelar, Coordenadoria Regional de Educação entre outros.

Com atuação do projeto no bairro de Senador Camará, foi possível compreendemos a necessidade e importância das ações intersetoriais, pois a falta de interlocução entre os serviços demostra a invisibilidade da população para o atendimento no território, deixando assim famílias inteiras em total condição de vulnerabilidade social, aqui entendida como, conforme preceitua a PNAS (2004):

... situação de vulnerabilidade social decorrente da pobreza, privação (ausência de renda, precário ou nulo acesso aos serviços públicos, dentre outros) e, ou, fragilização de vínculos afetivos - relacionais e de pertencimento social (discriminações etárias, étnicas, de gênero ou por deficiências, dentre outras) (BRASIL, 2004, p. 33).

Além de todas as precarizações dos serviços, as famílias vivenciam cotidianamente o processo de violência local que furta o direito de ir e vir a qualquer momento, pois há relatos de familiares que em dias de operação da policia e forte tiroteio no território não tem como mandar as crianças para a escola.

\footnotetext{
${ }^{2}$ Conflagrados onde o trafico e que dita às regras na comunidade.

${ }^{3}$ A falta do diálogo entre os equipamentos faz com que as famílias busquem resolução de suas demandas em diversos equipamentos, muitas vezes não alcançando resultados devido à burocratização das relações institucionais.
} 
Nas favelas do Rebu, Correia e Taquaral é muito expressivo a constante presença de grupos criminosos armados com poder de artilharia igual de um território de guerra. Isso dificulta muito a permanência da criança na escola, porque grande parte faz o percurso até a escola sem a companhia dos pais, estando desprotegidas no território no meio de operações policiais.

As questões de violência urbana atingem esta parte da população que fica vulnerável com presença de grupos criminosos armados em seu cotidiano, pois em territórios com grupos criminosos armados que detém o poder local, os espaços são fragmentados de acordo com a facção criminosa que domina a localidade. Desta forma, o direito de ir e vir fica cerceado, portanto a mobilidade dos moradores fica limitada, impossibitando que exerçam seu papel de cidadão comum e livre.

\section{Caminhos para a garantia do direito à educação em territórios conflagrados}

Os jovens de localidades mais vulneráveis convivem cotidianamente com situações de violência e pouca oferta de atrativos culturais, este é um dos fatores que ocasionam o desinteresse do jovem pela escolarização, dentre outros os quais não serão aqui abordados por não compreenderem o objetivo do trabalho.

Consideramos importante sinalizar que faz -se necessário que as equipes técnicas dos equipamentos públicos passem a ter um olhar sensível para questão dos limites territoriais impostos facções criminosas, compreendendo, inclusive os padrões estabelecidos pelo crime organizado para convivência local, e para esclarecer, citamos como exemplo, a alocação de alunos em determinadas unidades escolares, pois no período de matrículas online no momento de avaliação ${ }^{4}$ para possível ingresso em turmas de correção de fluxo ${ }^{5}$ acreditamos que deva ser levado em consideração qual o local de residência daquele aluno e qual a sua real situação, a fim de evitar que sejam encaminhados para territórios de facção rival.

$\mathrm{Na}$ tentativa de buscar alternativas para que este fator seja levado em conta, conseguimos articular com a coordenadoria de educação para modificar o site da matrícula, e com isto rever o lugar de avaliação, pois com esta pequena modificação será possível viabilizar a ida do aluno a um território neutro onde o

\footnotetext{
${ }^{4}$ Avaliação prova feita pela criança para verificar a real série que devera curar no ano seguinte.

${ }^{5}$ Turma de correção de fluxo Corrigir a defasagem entre idade e série dos alunos.
} 
poder paralelo não tem domínio da localidade, e assim facilitar a permanência do mesmo na escola, visto que:

As estatísticas relacionadas à Educação Básica nas comunidades populares dos centros urbanos são de difícil obtenção em muitos municípios por falta de levantamentos sistemáticos da situação nessas áreas. Os indicadores do Ministério da Educação (MEC), assim como todos os dados obtidos com base na Pesquisa Nacional por Amostra de Domicílios (Pnad) feita anualmente pelo IBGE, referem-se aos municípios e não a bairros e comunidades. O risco de uma criança que mora em uma comunidade popular ter atraso escolar na 4asérie do Ensino Fundamental, por exemplo, é 16\% maior do que o de uma criança que mora em outros bairros $A$ violência é também um problema enfrentado por boa parte da comunidade escolar, principalmente nas instituições localizadas nas comunidades populares de grandes cidades. Para cada escola definida como inserida num contexto tranquilo, pelo menos outra convive com problemas de segurança em seu entorno. (UNICEF,2009, p.107).

Outra estratégia efetivada pelo projeto Aluno Presente juntamente com as escolas de Senador Camará foi à importância de participar dos Conselhos de Classe e chamar atenção dos professores sobre a real realidade vivenciada cotidianamente pelas crianças que ali residem, e com isto foi possível perceber que havia um preconceito, hostilidade e discriminação por parte de alguns professores sobre esses alunos, mas gradativamente foram agregando novos valores a respeito da realidade e, consequentemente da vida dos alunos..

Também foram realizadas ações com as famílias na busca de orientá-las a respeito de mostrar a importância da permanência da criança no ambiente escolar, que somente através do acesso à educação será possível transformar a realidade na busca de um futuro melhor.

\section{Considerações finais}

As reflexões aqui desenvolvidas explicitam que a precariedade das políticas públicas no seu aspecto intersetorial ainda é muito grande, e se não houver um esforço por parte das equipes técnicas dos equipamentos públicos na importância da devida atenção e efetivo atendimento da população vulnerabilizada não iremos avançar e buscar resultados que viabilizem a garantia de direitos sociais. Os serviços públicos instalados nesses territórios têm como desafio achar medidas para diminuir os impactos nas ações de atenção à população beneficiárias das garantias de direito na busca de melhor qualidade de vida assim como a manutenção da permanência das crianças na escola.

Portanto, espera-se das diferentes esferas de governo que haja esforço no sentido de investir em serviços necessários para o alcance da construção contínua das ações intersetoriais com trabalho em redes, para que se possa 
garantir a cobertura dos atendimentos e ações desenvolvidas nas políticas educação, saúde e de assistência social, visando diminuir a precarização da oferta de serviços e combater as diversas formas de violação de direitos.

\section{Referências}

AMBROMOWAY, Miriam, et al. Juventude, violência e Vulnerabilidade Social na América Latina; desafios para políticas públicas. Brasília. UNESCO. BID. 2002. $192 \mathrm{p}$.

BEHRING, E. R.; BOSCHETTI, I. Política social: fundamentos e história. São Paulo : Cortez, 2008.

BRASIL. Constituição da República Federativa do Brasil. Diário Oficial. 1988. Diário Oficial do Rio de Janeiro. № 223, de 12 de fevereiro de 2015 Ministério do Desenvolvimento Social e Combate à Fome. Política Nacional de Assistência Social, 2004, Brasília: MDS, 2004. Ministério do Desenvolvimento Social e Combate à Fome. Tipificação Nacional dos Serviços Socioassistenciais, Resolução n.109 de 11 de novembro de 2009, Brasília: MDS, 2009.

FAUSTINO, Taiane. Q. S. A Intersetorialidade no Sistema Único de Assistência Social: um diálogo com a literatura atual. Revista Perspectivas em Políticas Públicas, Belo Horizonte: Faculdade de Políticas Públicas da UEMG, n. 14, p. 153-192, dez. 2014.

JUNQUEIRA, L.A.P. \& INOJOSA, R. M. Desenvolvimento social e intersetorialidade: a cidade solidária p 37. São Paulo, FUNDAP, 1997

JUNQUEIRA, L. A. P; In: A gestão intersetorial das políticas sociais e o terceiro setor. Saúde e Sociedade v.13, n.1, 2004.LAURELL, A. C.. (Org). Estado e Políticas Sociais no Neoliberalismo. São Paulo: Cortez, 1995.

MONNERAT, G. L.; SOUZA, R. G. Política social e intersetorialidade: consensos teóricos e desafios práticos. SER Social, Brasília, v. 12, n. 26, 2009.

MONNERAT, Giselle; SOUZA, Rosimary; ALMEIDA, Ney Luiz. A intersetorialidade na agenda das políticas sociais. São Paulo: Papel Social, 2014.

RAICHELIS, Raquel. Esfera pública e conselhos de assistência social: caminhos para construção democrática. São Paulo, Cortez, 2000.

UNICEF, Situação da Infância e da Adolescência Brasileira 2009 - O Direito de Aprender. DF: 2009. 
Sites consultados:

Disponível em<: http://alunopresente.org.br/wp-

content/uploads/2015/05/D.O. 12-02-2015 PSE-Carioca-3-4.pdf> Acesso 24/01/2017

Disponível em: <http://alunopresente.org.br/> Acesso 16/01/2017. 